\title{
Digitaal
}

\section{Het Taalportaal}

Een nieuwe wetenschappelijke grammatica voor het Nederlands en het Fries (en het Afrikaans)

Ton van der Wouden, Jenny Audring, Hans Bennis, Frits Beukema, Geert Booij, Hans Broekhuis, Norbert Corver, Crit Cremers, Roderik Dernison, Marcel den Dikken, Siebren Dyk, Carlos Gussenhoven, Ger de Haan, Vincent van Heuven, Eric Hoekstra, Jarich Hoekstra, Bart Hoogeveen, Gerbrich de Jong, Evelien Keizer, Anna Kirstein, Björn Köhnlein, Frank Landsbergen, Kathrin Linke, Marc van Oostendorp, Nina Ouddeken, Koen Sebregts, Carole Tiberius, Arjen Versloot, Willem Visser, Riet Vos, Truus de Vries en Joke Weening

\author{
NT 21 (1): 157-168 \\ DOI: 10.5117/NEDTAA2016.1.WOUD
}

\begin{abstract}
Taalportaal. A new scientific grammar of Dutch and Frisian (and Afrikaans)

We describe the Taalportaal, a new comprehensive on-line scientific grammar of Dutch and Frisian.
\end{abstract}

Keywords: grammatica, syntaxis, fonologie, morfologie, Nederlands, Fries

\section{$1 \quad$ Wat is het?}

Het Taalportaal (www.taalportaal.org) is een wetenschappelijke grammatica van het Nederlands en het Fries. Het doel van de grammatica is primair beschrijvend - hoewel theoretische discussies en standpunten bij gelegenheid niet uit de weg worden gegaan - en is, in elk geval in die zin, vergelijkbaar met het monumentale werk van Huddleston \& Pullum (2002). Het is de eerste grote grammatica van de twee officiële talen van Nederland die niet als papieren boek, maar digitaal gepubliceerd wordt het is dus een internetgrammatica. Er zitten verschillende voordelen aan zo'n internetgrammatica in vergelijking met een papieren boek. We noe- 
men er drie: hij is gratis toegankelijk voor iedereen (met een internetverbinding), de beschrijvingen kunnen geïllustreerd worden met geluidsfragmenten en met gegevens uit andere gegevensbronnen (woordenboeken, tekstcorpora, enz. - zie hieronder), en de mogelijkheid bestaat om de grammatica voortdurend bij te werken, waar een grammatica op papier verouderd is zodra die gedrukt is.

Het Taalportaal geeft een zo compleet mogelijk beeld van de klankstructuur (fonologie), de woordstructuur (morfologie) en de zinsstructuur (syntaxis) van het Nederlands en het Fries.

Technisch heeft het Taalportaal de vorm van een complexe XML-databank, die via een webbrowser geraadpleegd kan worden. De structuur van de teksten is vaak geïnspireerd door Wikipedia en vergelijkbare digitale kennisbronnen, met dit verschil dat de anarchie van dat soort projecten vermeden wordt, doordat alleen geautoriseerde deskundigen de teksten bewerken.

Door maximale integratie en uitputtende dwarsverwijzingen zijn de scheidslijnen tussen de traditioneel onderscheiden taalkundige deelgebieden zo goed als onzichtbaar: een vraag over overgankelijke werkwoorden biedt niet alleen syntactische informatie, maar ook morfologische en fonologische. Op deze wijze kunnen bijvoorbeeld correlaties zichtbaar gemaakt worden die anders wellicht verborgen zouden blijven. Denk bijvoorbeeld aan het feit dat overgankelijke werkwoorden van het type eten wel, maar van het type weten niet in de lijdende vorm kunnen voorkomen (wel de soep werd door mij gegeten maar niet *de weg werd door mij geweten) en anderzijds het feit dat er wel een bijvoeglijk naamwoord op -baar van eten, maar niet van weten gevormd kan worden (wel eetbaar maar niet *weetbaar). ${ }^{1}$

Het idee van een meertalig taalportaal sprak in Zuid-Afrika zó aan dat men voor het grammatica-deel van het project Virtuele Instituut Vir Afrikaans (VivA, zie www.viva-afrikaans.org), dat een digitale infrastructuur voor het Afrikaans ontwikkelt, graag participeert in het Taalportaal. De ontwikkeling van het Afrikaanse gedeelte is later gestart dan die van de Nederlandse en Friese delen, dus er zijn vooralsnog veel minder gegevens voor het Afrikaans beschikbaar. Er wordt evenwel hard aan gewerkt.

1 We konden niet zo gauw een fonologisch gegeven verzinnen dat specifiek op overgankelijke werkwoorden van toepassing is. In http://nederl.blogspot.com.es/2016/o2/verscherping.html demonstreert Marc van Oostendorp aan de hand va het Taalportaal dat verscherping (ook wel bekend als Auslautverhärtung en final devoicing) weliswaar een fonologisch proces van het Nederlands is, maar dat je het pas goed kunt begrijpen als je ook naar de morfologie, de syntaxis en de fonetiek kijkt - en naar het Fries. 
De beschrijving van de Friese taalfeiten is deels contrastief, dit gezien de grote taalkundige overeenkomsten tussen de twee talen en conform de traditie in de frisistiek. De nadruk ligt hier met name op de verschillen met het Nederlands. Daar waar het Nederlands en het Fries zich identiek gedragen volgen de beschrijvingen van de Friese taalfeiten die van het Nederlands.

De voorpagina van het Taalportaal ziet er als volgt uit:

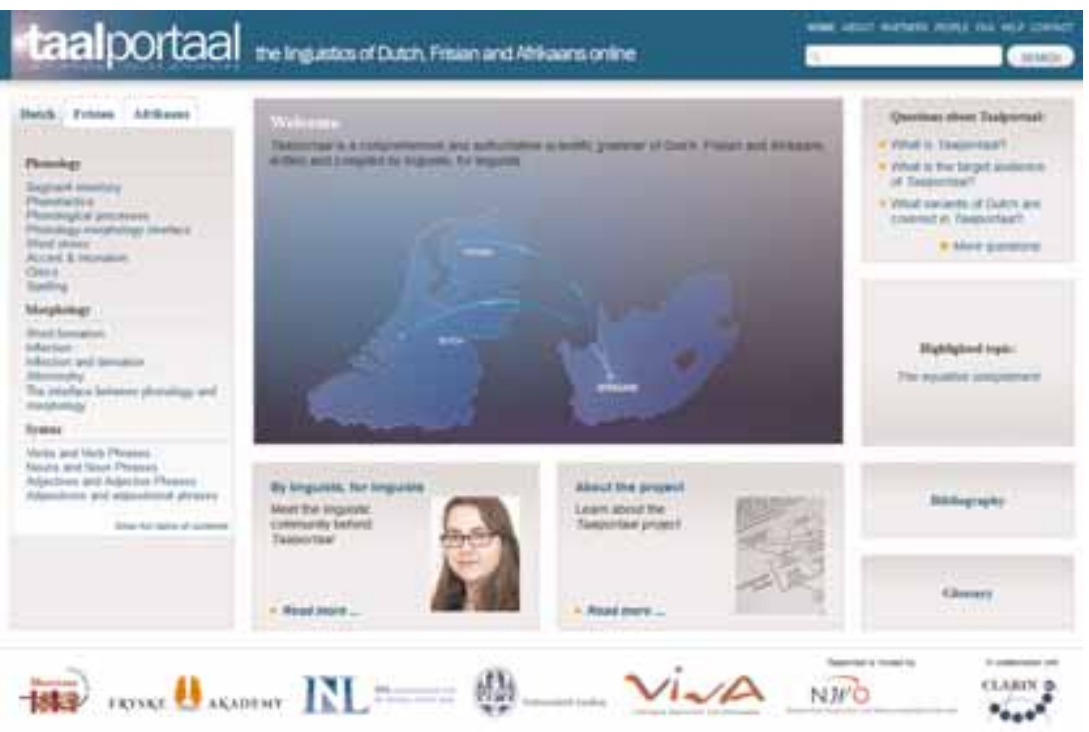

Aan de linkerkant van deze (volle) pagina staat een inhoudsopgave met tabbladen voor de drie talen. Ieder tabblad geeft op zijn beurt weer toegang tor de drie hoofddelen fonologie, morfologie en syntaxis voor de gekozen taal. Rechtsonder staan onder meer doorverwijzingen naar de uitgebreide bibliografie en een glossarium van gebruikte taalkundige termen.

\section{$2 \quad$ Voor wie?}

De doelgroep van het Taalportaal is primair de wetenschappelijke gemeenschap: niet alleen de neerlandicus of frisist intra of extra muros, maar ook alle andere taalkundigen, alsmede in taal geïnteresseerden uit aanpalende vakgebieden. Aangezien de wetenschap tegenwoordig zeer internationaal is, is het Engels de voertaal van het Taalportaal. Daarmee is het vergelijkbaar met de Syntax of Dutch (SoD, Broekhuis et al. 2012-2016, vergelijk ook Broekhuis \& Van Riemsdijk 1998). En net zomin als die SoD is het Taalportaal niet de eerst aangewezen bron voor een inleidend college taalkunde, al 
is het maar omdat het Taalportaal nogal wat taalkundige kennis voorondersteld. Gebruik in het onderwijs is zeker niet onmogelijk, maar dan als extra leesstof of als zelfstudiemateriaal voor gevorderde studenten, waar nodig met ondersteuning door een docent (cf. Broekhuis 2013).

Het Taalportaal richt zich dus bewust op een andere doelgroep dan de ANS, getuige de volgende passage uit de inleiding daarvan (Haeseryn et al. 1997):

De ANS moet gebruikt kunnen worden door een grote groep belanghebbenden die behoefte hebben aan de geboden informatie. Wat de anderstaligen betreft is de ANS niet bedoeld voor beginners, maar hoogstens voor de gevorderde student en zeker de docent in het Nederlands als tweede of vreemde taal; en dat is buiten Nederland en België lang niet altijd een gespecialiseerd neerlandicus en ook niet altijd een taalkundige. Bij de Nederlandstaligen valt niet alleen te denken aan docenten op academisch of middelbaar niveau, maar aan iedere ontwikkelde leek die voldoende basiskennis bezit om een uitvoerige Nederlandse grammatica te kunnen gebruiken.

\section{$3 \quad$ Door wie?}

Het Taalportaal is een samenwerkingsproject van het Meertens Instituut, de Fryske Akademy, het Instituut voor Nederlandse Lexicologie en de Universiteit Leiden. Bij de feitelijke totstandkoming zijn verschillende binnenen buitenuniversitaire instituten betrokken geweest. Het meeste geld kwam van NWO (NWO Groot 175.010.2009.003).

\section{$4 \quad$ Voorwerk}

Het Taalportaal kon alleen gebouwd worden dankzij een degelijk fundament. Het gedeelte over de Nederlandse syntaxis is vrijwel identiek aan de hierboven al genoemde Syntax of Dutch (Broekhuis et al. 2012-2016), die onder meer steunt op de Algemene Nederlandse Spraakkunst (ANS, Haeseryn et al. 1997). Ook voor de Nederlandse morfologie was de ANS een waardevolle bron, met name het eerste deel, en daarnaast natuurlijk het Morfologisch Handboek van het Nederlands (De Haas en Trommelen 1993), The Morphology of Dutch (Booij 2002) en het recent verschenen leerboek Basisbegrippen morfologie (Smessaert 2013, cf. ook Van der Wouden 2015). Voor de fonologie kon teruggevallen worden op The Phonology of Dutch 
(Booij 1995) en Fonologie: uitnodiging tot de klankleer van het Nederlands (Kooij en van Oostendorp 2003). Ook voor het Fries lag er al veel voorwerk, zoals Visser (1997), Hoekstra (1998), Tiersma (1999), Popkema (2006), en De Haan et al. (2010).

\section{$5 \quad$ Een voorbeeld}

Laten we de structuur en de inhoud van het Taalportaal illustreren aan de hand van een voorbeeld, verkleinwoordvorming. Dat is in het Nederlands een complex, maar goed onderzocht fenomeen (vergelijk ook Trommelen 1984) met fonologische, morfologische, syntactische en semantische/pragmatische aspecten; die zijn allemaal terug te vinden in het Taalportaal. Bovendien biedt het portaal de mogelijkheid tot vergelijking met het Fries (en op termijn ook met het Afrikaans).

Alle Taalportaal-pagina's hebben rechtsboven een zoekvakje:

\section{HOME ABOUT PARTNERS PEOPLE FAQ HELP CONTACT}

\section{diminutive}

SEARCH

Toen we daar op 24 januari 2016 diminutive intikten (de voertaal is immers Engels) kregen we meer dan honderd verwijzingen naar Taalportaalpagina's waarop het op de een of andere manier over verkleinwoorden gaat (tegen de tijd dat dit artikel in druk verschijnt, zijn het er ongetwijfeld al weer meer). Om de gebruiker te helpen de weg te vinden in die overdaad van informatie, zijn de zoekresultaten (automatisch) gesorteerd naar relevantie:

\section{Search results for diminutive (111)}

\section{Language Category}

$\begin{array}{ll}\text { Dutch (85) } & \text { Morphology (53) } \\ \text { Frisian (25) } & \text { Phonology (35) } \\ \text { Afrikaans (1) } & \text { Syntax (23) }\end{array}$

Bovenaan de zoekresultaten staan doorverwijzingen naar Nederlandse morfologie en fonologie. Het morfologische stuk is een lange lap tekst, met tal van voorbeelden, tabellen en literatuurverwijzingen. Ter illustratie 
geven we een heel klein stukje van het eind van het artikel - waar het gaat over syntactische én morfologische eigenschappen van verkleinwoorden:

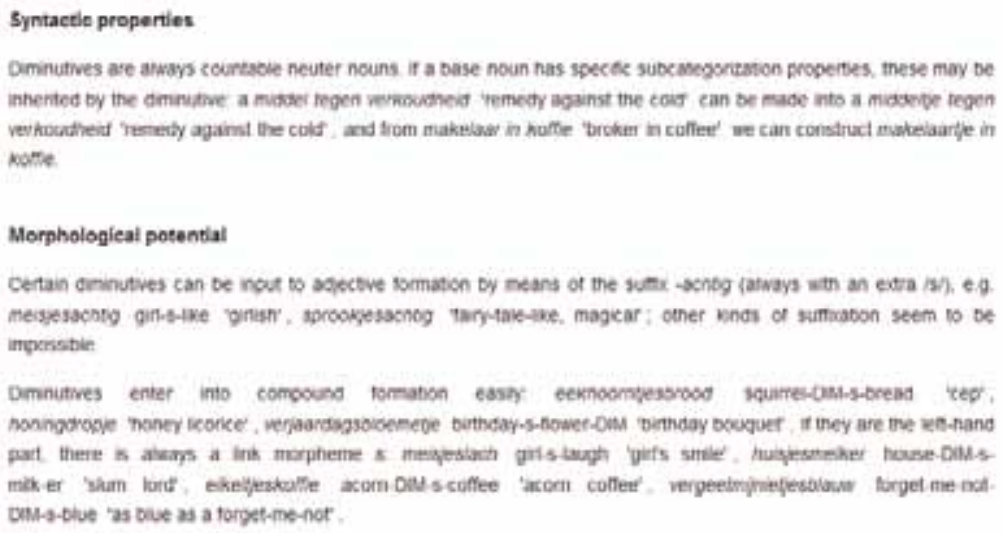

Het fonologische stuk is ook een flinke lap tekst, ook hiervan geven we een fragment:

\section{Diminutive allomorphy}

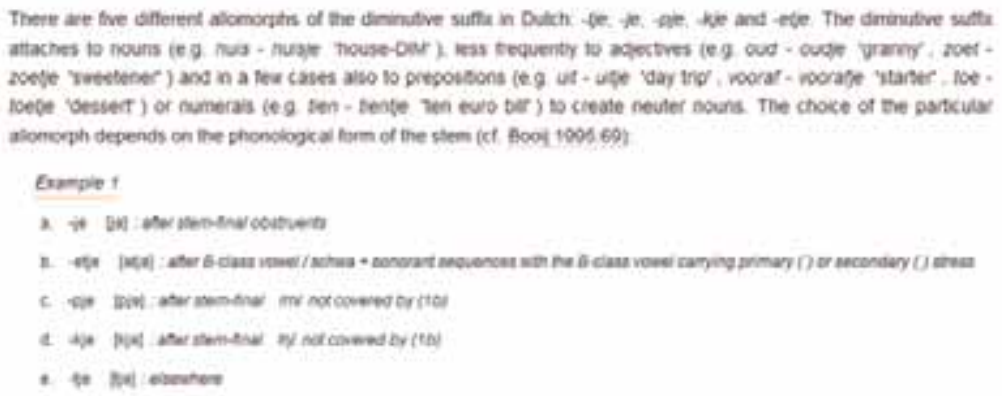

Vanzelfsprekend is er bij zo'n onderwerp als verkleinwoordvorming enige overlap tussen de morfologische en de fonologische behandeling van hetzelfde fenomeen, en in de morfologische afdeling komen ook bepaalde syntactische en semantische eigenschappen aan de orde. Dit kan haast niet anders: morfologie, syntaxis en fonologie zijn juist bij een fenomeen als verkleinwoordvorming onlosmakelijk met elkaar verknoopt. Daarnaast mag de gebruiker niet nodeloos lastiggevallen worden met te veel dwarsverwijzingen en doorklik-acties. We kunnen er voorts niet op rekenen dat de gebruiker lineair leest, we weten immers niet waar zijn belangstelling precies ligt. Gelukkig is redundantie bij een digitale grammatica veel minder een bezwaar dan in een papieren versie, al is het maar omdat er niet betaald hoeft te worden voor papier of drukinkt. 
De hoogste Friese verwijzing in de lijst van zoekresultaten is naar een hoofdstuk over final devoicing, een proces dat in het Fries ook bij verkleinwoorden optreedt:

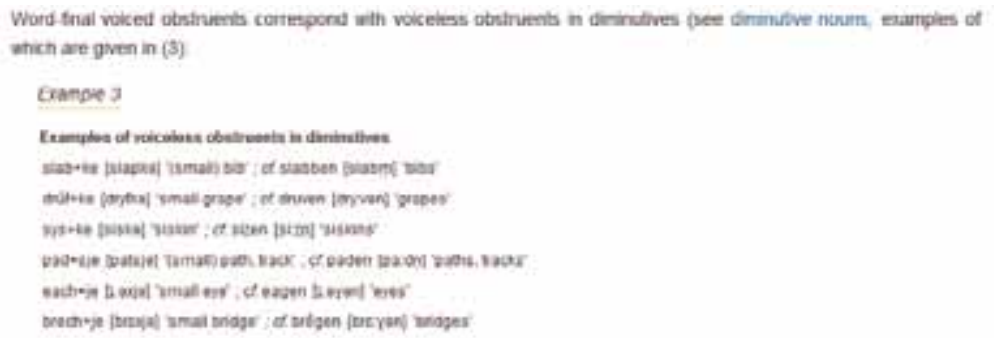

\section{$6 \quad$ Extra}

De taalkundig onderzoeker van de eenentwintigste eeuw wil steeds vaker nagaan of de feiten zoals die beschreven worden in de taalkundige literatuur ook overeenkomen met de taalkundige werkelijkheid zoals die terug te vinden is in feitelijk taalgebruik (vergelijk ook Hoeksema 2013). Dat zal evengoed gelden voor de gebruiker van het Taalportaal. Om die gebruiker van dienst te zijn is de taalkundige informatie in het Taalportaal verrijkt met links naar corpora. We kunnen twee soorten links onderscheiden:

- Er zijn links die automatisch gegenereerd zijn: zo kun je op vrijwel alle voorbeelden in het Taalportaal klikken, waardoor een pop-up-schermpje verschijnt (Landsbergen et al. 2014) en woordenboeken naar keuze. Welke er precies getoond worden hangt van het type voorbeeld (woord of zin) en de taal (Nederlands of Fries): bij woorden verschijnen er naast links naar corpora ook links naar online woordenboeken en naar de lexicale databank CELEX.

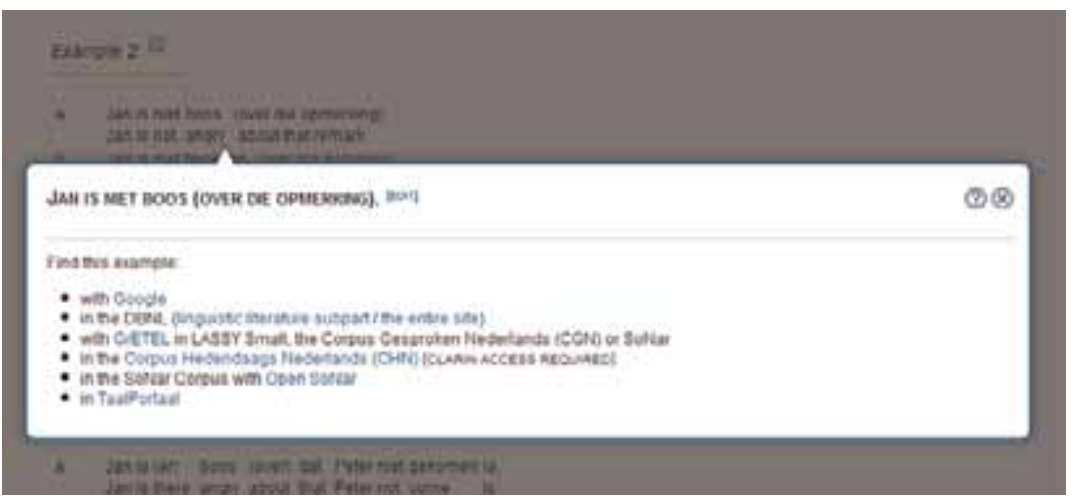


Als we in dit voorbeeld kiezen voor de derde optie, GrETEL, ${ }^{2}$ dan kunnen we, op een gebruiksvriendelijke manier en zonder dat we een complexe zoektaal hoeven te beheersen, naar syntactische structuren zoeken in een aantal grote geannoteerde corpora van het Nederlands. Het volgende plaatje geeft een stukje resultaat:

\begin{tabular}{|c|c|}
\hline 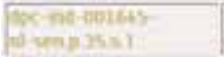 & 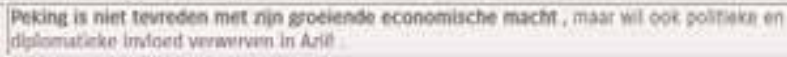 \\
\hline 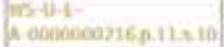 & Rottentam is ook bezig met zo'n plas. \\
\hline
\end{tabular}

Deze verbinding met andere taalkundige informatiebronnen is een duidelijk voorbeeld van de onmiskenbare meerwaarde die een digitale grammatica heeft boven een papieren exemplaar. ${ }^{3}$

- Er zijn ook links die niet automatisch gegenereerd zijn. Dankzij een aanvullende subsidie van CLARIN (CLARIN-NL-15-001: TPC) was het mogelijk student-assistenten fragmenten uit het Taalportaal (vooral uit het syntaxis-gedeelte) te laten verrijken met zoekopdrachten in geannoteerde corpora (vergelijk Bouma et al. 2015). Om in dat soort corpora te kunnen zoeken, moet de gebruiker meestal een speciale formele zoektaal leren (in dit geval XPATH); deze 'voorgebakken' zoekopdrachten omzeilen dat probleem. De zoekopdrachten zijn tamelijk uitgebreid gedocumenteerd - de vertaling van een stukje taalkundige beschrijving in een corpusquery is verre van triviaal; in het commentaar (Description in het plaatje hieronder) kan de annotator zijn interpretatie van het tekstfragment expliciet maken. Een voorbeeld kan dit wellicht verduidelijken:

\subsection{Prepositional complements}

The examples in (2) show that complements of adjectives are normally PPs, which are often optional

Deze passage is als volgt verrijkt:

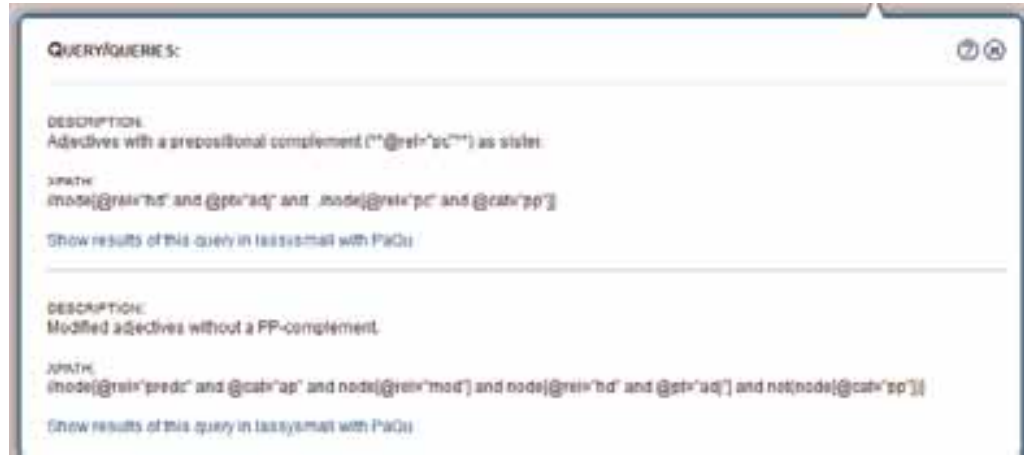


De annotator heeft de zin over adjectieven vertaald in twee query's: de eerste zoekt naar bijvoeglijke naamwoorden met een voorzetselcomplement (Adjectives with a prepositional complement as sister), de tweede naar nader bepaalde adjectieven zónder zo'n complement (Modified adjectives without a PP-complement). Aanklikken van de blauwe zoekregel Show results of this query in lassysmall with PaQu brengt de gebruiker naar de PaQu-interface (cf. Odijk 2015). De eerste zoekopdracht levert tal van zinnen uit het Lassy klein-corpus op. Hieronder staan de eerste drie:

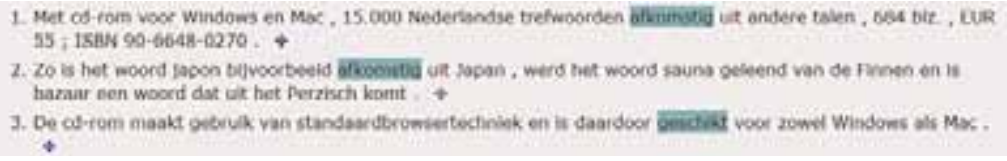

We zien twee keer het adjectief afkomstig gevolgd door een voorzetselgroep met uit, en een keer het adjectief geschikt met een voorzetselgroep met voor. De tweede zoekopdracht geeft ons onder veel meer de volgende drie zinnen:

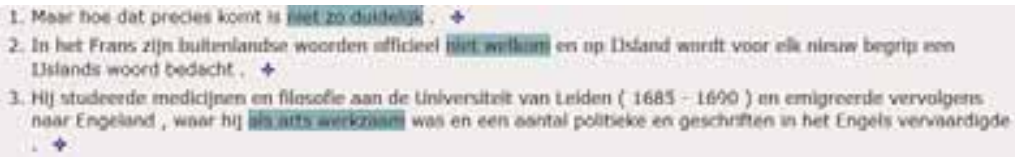

Hier zien we de drie bijvoeglijke naamwoorden duidelijk, welkom, en werkzaam, gemodificeerd met respectievelijk niet zo, niet, en als arts. Als de gebruiker in PaQu op het klavertje vier klikt, komt er ook nog een ontleedboom tevoorschijn. Verder kan er ook nog in andere corpora dan Lassy klein (cf. Van Noord et al. 2013) gezocht worden, en kan de opdracht naar believen veranderd worden.

\section{$7 \quad$ Tot besluit}

In dit artikel hebben we kort de doelen, de achterliggende filosofie en een aantal details besproken van het Taalportaal, een nieuwe wetenschappelijke internetgrammatica voor het Nederlands en het Fries - en binnenkort ook voor het Afrikaans, en daarna misschien nog wel voor andere talen. De deelnemende instituten hebben zich verplicht om het portaal up-to-date te houden, en ze hopen dat met dit portaal een belangrijk nieuw hulpmiddel is gecreëerd voor de taalkundige onderzoekswereld. Die is nu aan zet. 


\section{Referenties}

Augustinus, Liesbeth, Vincent Vandeghinste \& Frank Van Eynde (2012). Example-Based Treebank Querying. In: Proceedings of the 8th International Conference on Language Resources and Evaluation (LREC-2012). Istanbul, Turkey, 3161-3167.

Booij, Geert (1995). The Phonology of Dutch. Oxford: Oxford University Press.

Booij, Geert (2002). The Morphology of Dutch. Oxford: Oxford University Press.

Bouma, Gosse, Marjo van Koppen, Frank Landsbergen, Jan Odijk, Ton van der Wouden \& Matje van de Camp (2015). Enriching a Descriptive Grammar with Treebank Queries. In: M. Dickinson, E. Hinrichs, A. Patejuk \& A. Przepiórkowski (eds.), Proceedings of the Fourteenth International Workshop on Treebanks and Linguistic Theories (TLT14). Warsaw, Institute of Computer Science, Polish Academy of Sciences, 13-25.

Broekhuis, Hans (2013). De Syntax of Dutch: nieuw gereedschap voor de internationale neerlandistiek. Internationale Neerlandistiek 51(3), 243-26o.

Broekhuis, Hans Norbert Corver, Marcel den Dikken, Evelien Keizer \& Riet Vos (2012-16). Syntax of Dutch. Amsterdam: Amsterdam University Press (7 delen).

Broekhuis, Hans \& Henk van Riemsdijk (1998). Een grammatica voor taalkundigen: A modern Grammar of Dutch. Nederlandse Taalkunde 3(3), 282-29o.

de Haan, Germen, Jarich Hoekstra, Willem Visser \& Goffe Jensma (red.) (2010). Studies in West Frisian Grammar: Selected Papers by Germen J. de Haan. Amsterdam: John Benjamins.

de Haas, Wim \& Mieke Trommelen (1993). Morfologisch Handboek van het Nederlands. Den Haag: SDU uitgeverij.

Haeseryn, Walter, Kirsten Romijn, Guido Geerts, Jaap de Rooij, \& Maarten C. van den Toorn (1997). Algemene Nederlandse Spraakkunst, 2e, geheel herz. dr. Groningen en Deurne: Martinus Nijhoff and Wolters Plantijn.

Hoeksema, Jack (2013). Review of: Syntax of Dutch. Noun and Noun Phrases vols. 1 and 2. Lingua 133, 385-390.

Hoekstra, Jarich (1998). Fryske Wurdfoarming. Ljouwert: Fryske Akademy.

Huddleston, Rodney \& Geoffrey K. Pullum (in collab. with Laurie Bauer [et al.]) (2002). The Cambridge grammar of the English language. Cambridge [etc.]: Cambridge University Press.

Kooij, Jan \& Marc van Oostendorp (2003). Fonologie, uitnodiging tot de klankleer van het Nederlands. Amsterdam: University Press.

Landsbergen, Frank, Carole Tiberius \& Roderik Dernison (2014). Taalportaal: an online grammar of Dutch and Frisian. Proceedings of the Ninth International Conference on Language Resources and Evaluation (LREC '14). Reykjavik, Iceland: European Language Resources Association (ELRA), 2206-2210.

van Noord, Gertjan, Gosse Bouma, Frank van Eynde, Daniel de Kok, Jelmer van der Linde, Ineke Schuurman, Erik Tjong Kim Sang \& Vincent Vandeghinste (2013). Large scale syntactic annotation of written Dutch: Lassy. P. Spyns \& J. Odijk (red.), Essential Speech and Language Technology for Dutch: the STEVIN Programme. Springer, 147-164.

Odijk, Jan (2015). Linguistic Research with PaQU. Computational Linguistics in The Netherlands journal 5, 3-14.

van Oostendorp, Marc \& Ton van der Wouden (1998). Corpus internet. Nederlandse Taalkunde 3, 347-361.

Popkema, Jan (2006). Grammatica Fries: de regels van het Fries. Utrecht: Prisma.

Smessaert, Hans (2013). Basisbegrippen morfologie. Leuven/Den Haag: ACCO.

Tiersma, Piter Meijes (1999). Frisian Reference Grammar, 2e dr. Ljouwert: Fryske Akademy. 
Trommelen, Mieke (1984). The syllable in Dutch: with special reference to diminutive formation. Dordrecht: Foris.

Visser, Willem (1997). The Syllable in Frisian. Proefschrift Vrije Universiteit (Holland Academic Graphics).

van der Wouden, Ton (2015). Een buitengewoon bruikbaar leerboek. Internationale Neerlandistiek $53(2), 173^{-176}$.

\section{Over de auteur}

Ton van der Wouden, Universiteit Leiden

E-mail: a.van.der.wouden@hum.leidenuniv.nl 
